\section{Use of thyroid hormones after cardiopulmonary bypass in children}

$\mathrm{I}$

READ WITH GREAT INTEREST THE PAPER OF

Mainwaring and his colleagues concerning the Luse of supplementation of triiodothyronine following the modified Fontan procedure. ${ }^{1}$ The authors found an evident reduction in levels of triiodothyronine in the blood both during and after cardiopulmonary bypass in patients undergoing the Fontan procedure. We have encountered similar findings in 47 consecutive children undergoing surgery for various heart defects, and observed that the changes did not depend on age, body weight, the type of the heart defect, nor on the depth of hypothermia achieved during the operation. ${ }^{2}$ Mainwaring et all gave triiodothyronine as a bolus at a dose of $0.2 \mathrm{mcg} / \mathrm{kg}$ immediately after the operation, and administered a similar dose over 6 hours in the intensive care unit. They obtained an improved clinical outcome, as well as observing faster recovery of thyroid hormones in the blood following the procedure. This group of patients seems to be most amenable to treatment with triiodothyronine, which combines positive inotropic and vasodilatory effects. My findings in infants with low cardiac output postoperatively were similar, and make me think that triiodothyronine has a moderately positive influence in such circumstances. ${ }^{3}$ The optimal dosage to be given after cardiopulmonary bypass, however, has not yet been determined. In animal experiments, the treatment was dose-dependent. ${ }^{4}$ I gave triiodothyronine to 14 infants with low cardiac output postoperatively after various operations (arterial switch, total correction of tetralogy of Fallot, correction of complete atrioventricular septal defect, and closure of ventricular septal defect) according to two different protocols. In the first protocol, used in 7 children, triiodothyronine, given as Thyreotardin-inject. $\mathrm{N}$, was administered as an intravenous bolus at a strength of 0.4 $\mathrm{mcg} / \mathrm{kg}$, and was followed by an infusion of 0.2 $\mathrm{mcg} / \mathrm{kg} / \mathrm{hr}$ for 8 hours. This dosage was comparable to that used by Rosen and colleagues in children, ${ }^{5}$ and by Cimochowski et al in adults, ${ }^{6}$ but was lower than the dosage administered by Novitzky and associates to some of their high-risk patients undergoing open heart procedures. ${ }^{7}$ In one of our infants with Down's syndrome and tetralogy of Fallot, an unusual complication occurred after administration of triiodothyronine according to the above mentioned regimen, but given for 14 instead of 8 hours. In this patient, we noted persistent hypotension with markedly increased warmth of the arms and legs. Acute renal failure developed despite giving an infusion of norepinephrine. After haemofiltration, which probably eliminated the excessive amount of triiodothyronine, cardiovascular as well as renal functions returned to normal. As far as I know, this is the first complication encountered of this kind, although reduction of systemic vascular resistance requiring administration of vasoconstrictive drugs has been described after higher dosages of triiodothyronine. ${ }^{6}$ In our second protocol, we gave triiodothyronine to another 7 infants with low cardiac output postoperatively as a 0.4 $\mathrm{mcg} / \mathrm{kg}$ bolus followed by a maintenance infusion of $0.4 \mathrm{mcg} / \mathrm{kg}$ for 24 hours. No such complications were observed. An interesting alternative for treatment of postoperative cardiac failure in children is the use of thyroxine. This has been given with good results by Andreas Urban at $\mathrm{St}$ Augustin's Hospital in Germany for several years (personal communication). The main advantage of treatment with thyroxine is the provision of a more physiological control of the concentrations of triiodothyronine in the serum, this being synthesized in extrathyroid tissue from the ingested thyroxine. This also has a beneficial effect on renal function. ${ }^{8}$ In keeping with my own initial experience, therefore, delivery of a $3 \mathrm{mcg} / \mathrm{kg}$ bolus of thyroxin (L Thyroxin Henning inject.) followed by continuous infusion of triiodothyronine at a dosage of $0.4 \mathrm{mcg} / \mathrm{kg} / 24 \mathrm{hrs}$ is another promising and safe alternative for treatment of low cardiac output postoperatively.

\section{References}

1. Maınwarıng RD, Lambertı JJ, Nelson JC, Bıllman GF, Carter TL, Schelli KH Effects of truodothyronine supplementation following modified Fontan procedure Cardiol Young 1997;7:194-200.

2. Bialkowskı J, Rubı J, Valıno JM, Sanchez PA, Dominguez F, Pallares E, Alonso A, Perez de Leon $J$ Effect of 
cardiopulmonary bypass upon thyroid hormones in children. Cir Cardiov 1997;4:33-38.

3. Bialkowski J. Triiodothyronine supplementation in infants after cardiac surgery. Abstracts of the Second World Congress of Pediatric Cardiology and Cardiac Surgery, Honolulu, 11-15.05.1997: 378 .

4. Walker JD, Crawford FA, Mukherjee R, Zile MR, Spinale FG. Direct effects of acute administration of 3,5,3'triiodo-Lthyronine on myocyte function. Ann Thorac Surg 1994;58:851-856.

5. Rosen D, Serafini ME, Philips LA, Stenner MA, Ashton CA, Gustafson RA. Thyroid hormone for children with cardiac failure. Crit Care Med 1996;24 (suppl):391 (abstract)

6. Cimochowskı GE, Harstock MD, Foldes PJ. Minimal operative mortality in patients undergoing coronary artery bypass with significant left ventricular dysfunction by maxımızation of metabolic and mechanical support. J Thorac Cardiovasc Surg 1997;113:655-666.

7. Novitzky D, Fontanet H, Synder M, Coblo N, Smith D, Parsonnet V. Impact of triiodothyronine on the survival of high-risk patients undergoing open heart surgery. Cardiology 1996;87:509-515

8. Siegel NJ Ask the Expert. Ped Nephrol 1990;4:358.

Jacek Bialkowski, MD

Paediatric Cardiology Dept Silesian Center for Heart Diseases ul.Szpitalna 2, 41800 Zabrze,

Poland

The letter of Dr Bialkowski was shown to Dr Mainuaring and his colleagues, who responded as follows:-

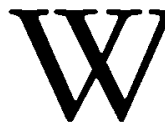

E THANK DR JaCEK BIALKOWSKI FOR his comments on our manuscript "Effects of triiodothyronine supplementation following modified Fontan procedure". It would appear from his comments that he, too, has found supplementation with triiodothyronine a useful adjunct in the postoperative management of children undergoing cardiopulmonary bypass. It is evident that children have a higher metabolic rate than adults and, therefore, will have differences in their pharmacokinetics. To this end, we are currently performing a pharmacokinetic study of the use of triiodothyronine following the Fontan procedure (Department of Health \& Human Services, Food \& Drug Administration Grant FDR-001195). This is a randomized prospective, double-blinded study with a group receiving placebo compared with three schedules of dosage with triiodothyronine $(0.4,0.6$, and 0.8 micrograms per kilogram). Thus far, we have enrolled 24 patients, and we have not observed adverse effects in this range of dosage. This experience confirms the impression that the agent is safe for administration to infants and children.

In addition to safety and pharmacokinetics, the third aspect of determining whether a drug has a useful application is its efficacy. Supplementation of triiodothyronine has been studied in adults undergoing cardiopulmonary bypass in whom cardiac output is measured by thermodilution using a Swan-Ganz catheter. Supplementation with triiodothyronine results in a dose-dependent increase in cardiac output. This increase in cardiac output, however, probably benefits only those patients who have low cardiac output. Boosting a normal cardiac output to a supra-normal level probably does not enhance recovery. Unfortunately, the monitoring of cardiac output in infants and small children is much more difficult, as evidenced by the Fontan patients who have residual shunting both from right-to-left, (coronary sinus, fenestrated Fontan) and left-to-right (aortopulmonary collaterals). These shunts render ineffective the conventional methodologies used to determine cardiac output. In their absence, it is more difficult to prove that triiodothyronine supplementation is efficacious. Measures of clinical outcome which we have followed include physical assessment of cardiac output, length of time on the ventilator, length of time in intensive care unit, and total length of hospital stay. These measures were improved in patients who received triiodothyronine, but are either subjective or somewhat alterable. The only hard data to indicate that supplementation is efficacious are those which indicate that patients receiving triiodothyronine have a more rapid endocrinologic recovery than patients who did not receive this medication. While these data are clear, they are admittedly a bit obscure.

Since the euthyroid sick syndrome induced by cardiopulmonary bypass is an acute illness, we believe that dosage with triiodothyronine will be more effective than supplementation using thyroxine. This is founded on the premise that triiodothyronine is immediately effective, whereas thyroxine must first be converted to triiodothyronine by $5^{\prime}$-deiodinase, the very enzyme which malfunctions and is the cause of the low levels of triiodothyronine in the euthyroid sick syndrome. Conversion of thyroxine to triiodothyronine is slow, and will not boost levels of triiodothyronine (and cardiac output) early postoperatively. The pharmacokinetic studies reveal, nonetheless, that supplementation with triiodothyronine results in serum levels which have a nadir at 24 hours. It is conceivable, therefore, that the optimal effect could be achieved by using a combination of these hormones.

Richard D Matnuaring Jerald C Nelson

3030 Children's Way, Suite 310 San Diego, CA 92123

USA 